\title{
Preparation of Single-Phase ZnSb Thermoelectric Materials Using a Mechanical Grinding Process
}

\author{
Chinatsu Okamura*, Takashi Ueda* and Kazuhiro Hasezaki \\ Department of Materials Science, Shimane University, Matsue 690-8504, Japan
}

\begin{abstract}
Single-phase zinc antimonide ( $\mathrm{ZnSb}$ ) was prepared using a mechanical grinding (MG) process. The ZnSb source ingots were prepared by direct melting of the constituent elements. Two processes were used to prepare the ingots. One of the processes involved quenching the molten material in water in an evacuated quartz ampoule. In the other process, an additional step consisting of heating for $100 \mathrm{~h}$ at $723 \mathrm{~K}$ was performed after quenching. The ground materials were obtained by mechanically grinding the resultant ingots and then hot-pressing at $673 \mathrm{~K}$. The materials were characterized by X-ray diffraction (XRD), differential thermal analysis (DTA), and thermoelectric property measurements. The results indicated that the materials were crack free and single phase. The thermal conductivity of the ground materials was $1.41 \mathrm{Wm}^{-1} \mathrm{~K}^{-1}$ at room temperature. This value was lower than that reported in the available data for materials prepared by conventional melt growth and powder metallurgy methods. The $\mathrm{ZnSb}$ single phase was found to have a dimensionless figure of merit of $0.6-0.8$ at $573 \mathrm{~K}$. [doi:10.2320/matertrans.MH200902]
\end{abstract}

(Received October 29, 2009; Accepted January 7, 2010; Published February 17, 2010)

Keywords: thermoelectric material, ZnSb, mechanical grinding, thermal conductivity, zinc, antimony

\section{Introduction}

Zinc antimonide $(\mathrm{ZnSb})$ is a thermoelectric material of potentially high performance in the intermediate temperature range (450-650 K). The constituent elements of $\mathrm{ZnSb}$ are low cost and non-toxic. ${ }^{1)} \mathrm{ZnSb}$ is therefore more environmentally sound than lead telluride, which is toxic.

Thermoelectric energy conversion results from the Peltier and Seebeck effects. The performance of thermoelectric materials is estimated using the figure of merit $Z T$, defined as $Z T=\alpha^{2} \sigma T \kappa^{-1}$, where $\alpha$ is the Seebeck coefficient $\left(\mathrm{VK}^{-1}\right)$, $\sigma$ is the electrical conductivity $\left(\Omega^{-1} \mathrm{~m}^{-1}\right), \kappa$ is the thermal conductivity $\left(\mathrm{Wm}^{-1} \mathrm{~K}^{-1}\right)$ and $T$ is the absolute temperature (K). Thermoelectric performance is enhanced by increasing the Seebeck coefficient and the electrical conductivity, and by decreasing the thermal conductivity.

Melt growth and powder metallurgy methods have been used to prepare $\mathrm{ZnSb}^{2-7)}$ Telkes has investigated the production of solar thermoelectric generators using $p$-type $\mathrm{ZnSb}^{2-5)}$ However, according to reports in the available literature, ${ }^{9,10)}$ preparation of single-phase $\mathrm{ZnSb}$ has proved to be difficult. $\mathrm{ZnSb}$ undergoes a peritectic reaction at $819 \mathrm{~K}$, indicating that prolonged heating is necessary to obtain single-phase $\mathrm{ZnSb}{ }^{8}$ )

Processes such as mechanical alloying (MA) and mechanical grinding (MG), which produce finely ground metal powders, have been used to obtain homogeneous materials. $^{9-12)}$ In general, finely ground materials have lower thermal conductivities than those of single crystals of the same materials because phonons can be scattered at grain boundaries. However, single-phase $\mathrm{ZnSb}$ has not been obtained by MA. ${ }^{9-12)}$ It has been reported that ductile $\mathrm{Zn}$ does not participate in mechanical alloying reactions, leading to $\mathrm{Zn}$ deficiency. ${ }^{11)}$ In the present study, MG was applied to $\mathrm{ZnSb}$ preparation, and two different methods of heat treating the melt growth ingots before grinding and sintering were investigated.

*Graduate Student, Shimane University

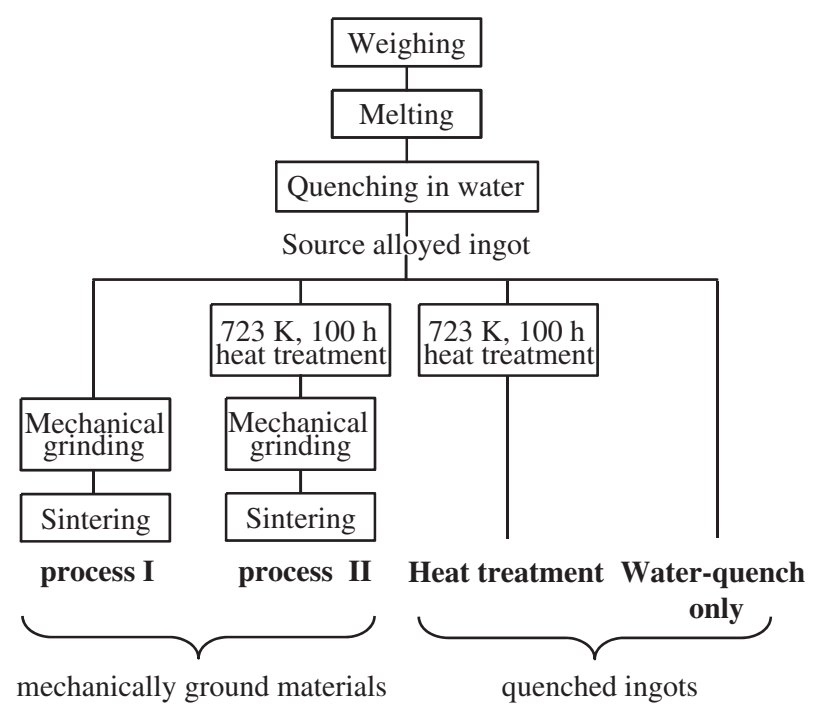

Fig. 1 Schematic diagram of the MG process for preparation of $\mathrm{ZnSb}$.

\section{Experimental Procedures}

$\mathrm{ZnSb}$ was prepared using two different MG processes. Figure 1 shows a schematic diagram of the MG processes.

MG process I consisted of making source ingots from the $\mathrm{ZnSb}$ melt, mechanical grinding (MG), and sintering. The source ingot was prepared by direct melting of $\mathrm{Zn}$ (99.9999\%) and Sb (99.9999\%) in an evacuated quartz ampoule at $923 \mathrm{~K}$ for $3 \mathrm{~h}$, and quenching the $\mathrm{ZnSb}$ melt in the ampoule in water. The resultant quenched ingot was put into a stainless steel vessel and milled with silicon nitride balls. The grinding was carried out in a planetary ball mill for $100 \mathrm{~h}$ at a maximum speed of $180 \mathrm{rpm}$. The pulverized powders were then sieved and passed through the size of $150 \mu \mathrm{m}$ in diameter. The pulverized powder was then set in stainless steel dies. The ground materials were obtained by hotpressing at a sintering temperature of $673 \mathrm{~K}$ under a mechanical pressure of $147 \mathrm{MPa}$ in an argon atmosphere. 
In MG process II, the quenched ingots underwent an additional heat-treatment at $723 \mathrm{~K}$ for $100 \mathrm{~h}$ to produce a homogeneous single-phase material.

The densities of the materials prepared by the MG processes were measured at room temperature using the Archimedes method. Metallographic observations were made using an optical microscope. The materials were also investigated by X-ray diffraction (XRD) using $\mathrm{Cu} \mathrm{K} \alpha$ radiation in a $2 \theta$ range of $20^{\circ}-50^{\circ}$, and by differential thermal analysis (DTA). DTA measurements were made by heating the material to $873 \mathrm{~K}$ at a rate of $20 \mathrm{~K} \mathrm{~min}^{-1}$ in an argon atmosphere in alumina containers.

The thermoelectric properties were measured using a ResiTest8340 (Toyo Corporation). The equipment has a measurement error of less than $1 \%$. The Seebeck coefficients $\alpha$ were estimated from the linear relationship between the thermoelectromotive force $(E)$ and a temperature difference $(\Delta T)$ of up to $3 \mathrm{~K}$, under vacuum over a temperature range of 300-573 K $\left(\alpha=E \Delta T^{-1}\right)$. The electrical conductivities $\sigma$ were measured by the van der Pauw method under vacuum over a temperature range of $300-573 \mathrm{~K}$. The thermal conductivities $\kappa$ of the mechanically ground materials were measured using the self-constructed instrument of static comparison method at room temperature. ${ }^{13)}$

Thermoelectric performances were evaluated using the dimensionless thermoelectric figure of merit $Z T$, where $Z T=\alpha^{2} \sigma T \kappa^{-1}$.

\section{Results and Discussion}

Many cracks and pores were observed in the quenched ingots produced by process I. This indicated that thermal stress occurred during quenching and the accompanying transformations. The relative densities of the mechanically ground materials after process I and after process II are listed in Table 1. All the materials had relative densities of more than $99 \%$; the theoretical density was $6.38 \mathrm{~g} \mathrm{~cm}^{-3} .{ }^{14}$ ) The results indicate that in both process I and process II pulverizing and sintering were necessary to obtain dense materials.

Figure 2 shows the XRD patterns of the mechanically ground materials and of the quenched ingots. All the observed diffraction peaks were identified as those of the $\mathrm{ZnSb}$ single phase.

Figure 3 shows the DTA curves for the mechanically ground materials. Increasing the temperature caused the formation of a small endothermic peak at $780 \mathrm{~K}$ corresponding to a eutectoid reaction between $\mathrm{ZnSb}$ and $\mathrm{Sb}$. The large endothermic peak at $823 \mathrm{~K}$ corresponds to the melting point of $\mathrm{ZnSb}$. These XRD and DTA results consistently indicated that single-phase $\mathrm{ZnSb}$ was produced by both of the MG

Table 1 Thermal conductivities and relative densities at room temperature for mechanically ground materials.

\begin{tabular}{cccc}
\hline Sample & $\begin{array}{c}\text { Thermal conductivity, } \kappa \\
\left(\mathrm{Wm}^{-1} \mathrm{~K}^{-1}\right)\end{array}$ & $\begin{array}{c}\text { Density } \\
\left(\mathrm{g} \mathrm{cm}^{-3}\right)\end{array}$ & $\begin{array}{c}\text { Relative density } \\
(\%)\end{array}$ \\
\hline process 1 & 1.41 & 6.36 & 99 \\
process 2 & 1.36 & 6.34 & 99 \\
\hline \multicolumn{4}{r}{ (Theoretical density: $\left.6.38 \mathrm{~g} \mathrm{~cm}^{-3}\right)^{14)}$}
\end{tabular}

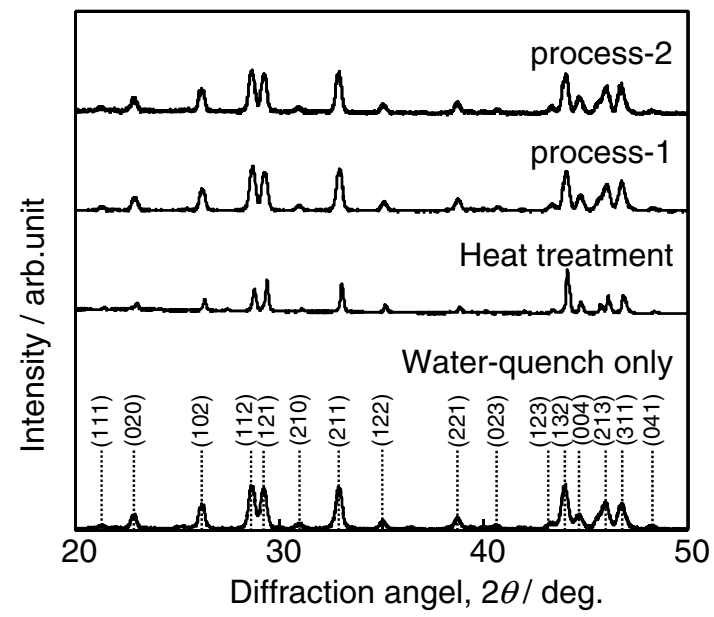

Fig. 2 XRD patterns of mechanically ground materials and of quenched ingots. Single-phase $\mathrm{ZnSb}$ was obtained using both $\mathrm{MG}$ process I and MG process II.

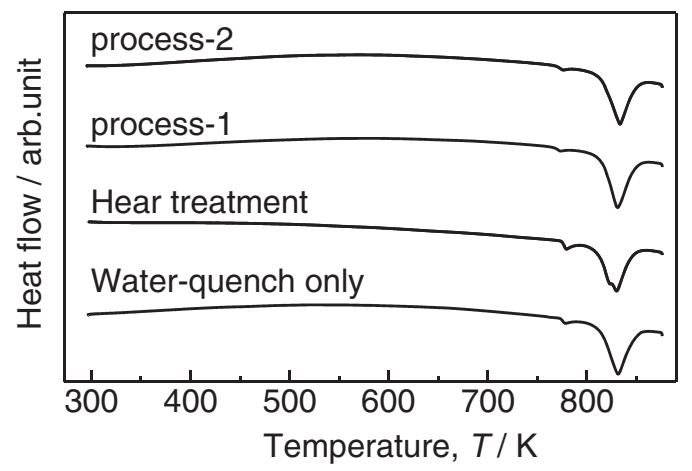

Fig. 3 DTA curves of mechanically ground materials and of quenched ingots.

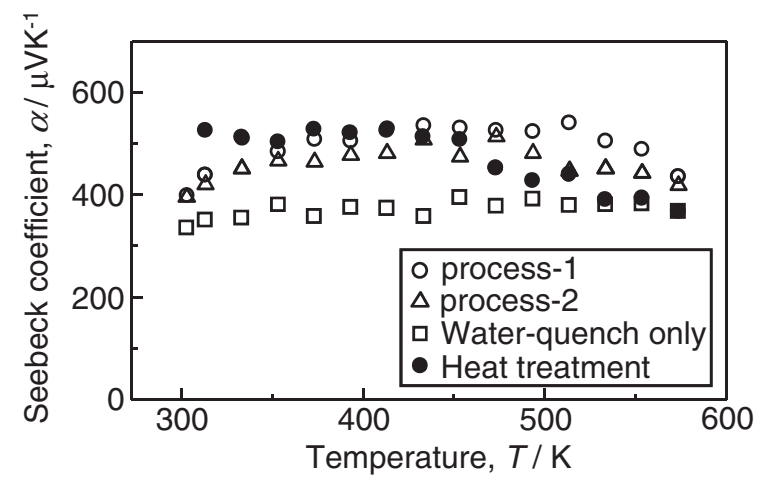

Fig. 4 Seebeck coefficient versus temperature for mechanically ground materials and for quenched ingots.

processes. It is considered that brittle $\mathrm{ZnSb}$ ingots are easy to pulverize.

Figures 4-6 show plots of thermoelectric properties versus temperature for the mechanically ground materials. The materials were $p$-type; their Seebeck coefficients $\alpha$ were all similar and were in the range $400-500 \mu \mathrm{V} \mathrm{K}^{-1}$ at room temperature. $\alpha$ values showed similar behavior to that of the temperature dependence (Fig. 4). At room temperature, the electrical conductivities $\sigma$ of the mechanically ground 


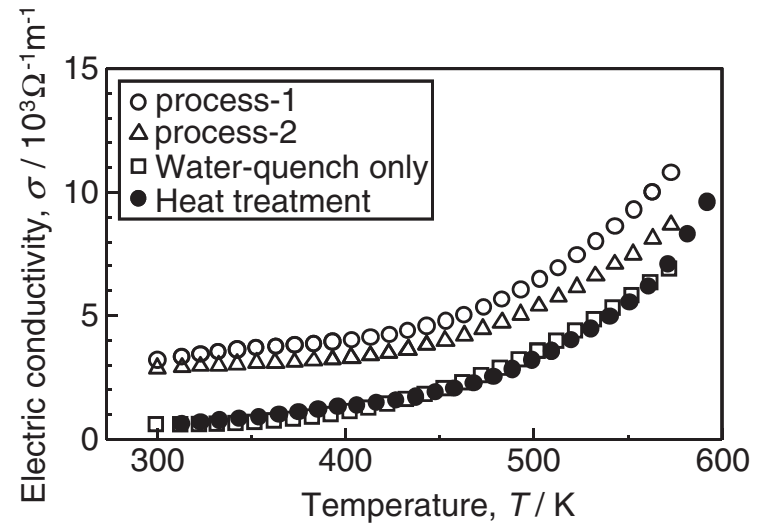

Fig. 5 Electrical conductivity versus temperature for mechanically ground materials and for quenched ingots.

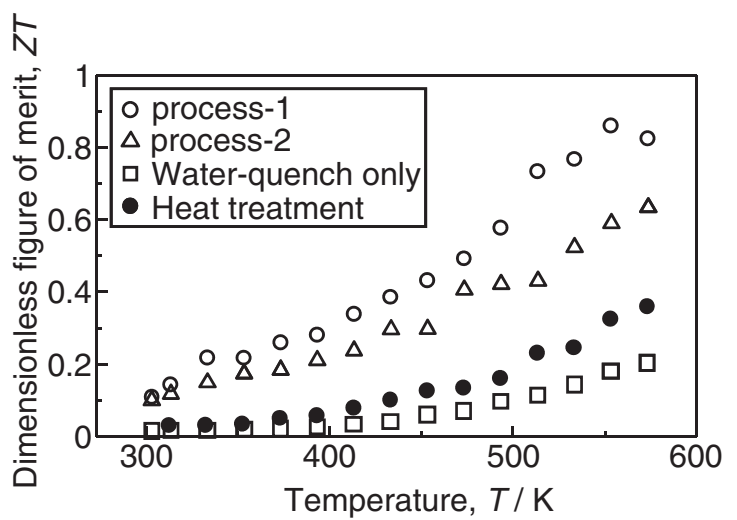

Fig. 6 Dimensionless thermoelectric figure of merit versus temperature for mechanically ground materials and for quenched ingots. The thermal conductivity was calculated using fixed values measured at room temperature.

materials were in the range $2.88 \times 10^{3}$ to $3.21 \times 10^{3}$ $\Omega^{-1} \mathrm{~m}^{-1}$, while $\sigma$ values for the quenched ingots were in the range $0.54 \times 10^{3}$ to $0.66 \times 10^{3} \Omega^{-1} \mathrm{~m}^{-1}$. The values for the quenched ingots were lower than those obtained for the mechanically ground materials. This may be because the quenched ingots had many microcracks. There were many similarities between the plots of $\sigma$ values versus temperature for the quenched ingots and for the mechanically ground materials (see Fig. 5).

The thermal conductivity $\kappa$ of the mechanically ground materials was $1.41 \mathrm{Wm}^{-1} \mathrm{~K}^{-1}$ at room temperature (see Table 1), which was lower than the values reported for materials prepared using conventional melt growth and powder metallurgical methods. ${ }^{15)}$ This showed that the MG process produced finely ground $\mathrm{ZnSb}$, resulting in decreased thermal conductivity.

Figure 6 shows a plot of the dimensionless thermoelectric figure of merit $(Z T)$ versus temperature for the mechanically ground materials and for the quenched ingots. The $Z T$ values for the mechanically ground materials were $0.6-0.8$ at $573 \mathrm{~K}$; the fixed value room temperature thermal conductivities were adopted. For the quenched ingots, $\kappa=2.7 \mathrm{Wm}^{-1} \mathrm{~K}^{-1}$ was used. ${ }^{15)}$

These results indicated that heat-treatment in the $\mathrm{MG}$ process did not result in appreciable differences in the Seebeck coefficients, electrical conductivities, or dimensionless thermoelectric figures of merit of the materials. Therefore, MG process I is a simple method for the preparation of single-phase and crack-free $\mathrm{ZnSb}$ materials.

\section{Conclusions}

In the present study, two MG processes (I and II) were used to prepare single-phase $\mathrm{ZnSb}$. Process II included additional heat-treatment to obtain a homogeneous material. The results are summarized as follows:

(1) Single-phase, dense ZnSb was successfully prepared by MG processes which consisted of preparing the source ingots from a $\mathrm{ZnSb}$ melt, grinding the ingots, and hot-pressing. The quenched ingots had many cracks and pores. Thus, grinding and sintering were necessary to obtain dense, homogeneous materials.

(2) The thermal conductivities of the mechanically ground materials reached $1.41 \mathrm{Wm}^{-1} \mathrm{~K}^{-1}$ at room temperature, a value which is lower than that reported for other available materials.

(3) All of the mechanically ground materials were $p$-type, with a dimensionless thermoelectric figure of merit in the range $0.6-0.8$ at $573 \mathrm{~K}$.

(4) MG process I was found to be a simple method for the preparation of single-phase, crack-free $\mathrm{ZnSb}$.

\section{REFERENCES}

1) Y. Suga: Thermoelectric Semiconductor, (Maki Shoten, Tokyo, 1966) pp. 314-317.

2) M. Telkes: U. S. Patent, 2, 229 (1941) 482.

3) M. Telkes: U. S. Patent, 2, 366 (1945) 881.

4) M. Telkes: J. Appl. Phys. 18 (1947) 1116-1127.

5) M. Telkes: J. Appl. Phys. 25 (1954) 765-777.

6) H. Komiya, K. Masumoto and H. Y. Fan: Phys. Rev. 133-A (1964) 1679-1684.

7) T. Ueda, C. Okamura, Y. Noda and K. Hasezaki: Mater. Trans. 50 (2009) 2473-2475.

8) H. W. Mayer, I. Mikhail and K. Schubert: J. Less Common Metals 59 (1978) 43-52.

9) K. Hasezaki, M. Nishimura, M. Umata, H. Tsukuda and M. Araoka: 12th Int. Conf. on Thermoelectrics, (ICT 1993) pp. 307-310.

10) T. Koyanagi, K. Adachi, K. Kishimoto and K. Matsubara: Trans. Inst. Elect. Eng. Jpn. 116-A (1996) 258-267.

11) S.-C. Ur, P. Nash and I.-H. Kim: J. Mater. Sci. 38 (2003) 3553-3558.

12) D. M. Trichês, S. M. Souza, J. C. de Lima, T. A. Grandi and C. E. M. Campos: J. Appl. Phys. 105 (2009) 063518.

13) T. Hamachiyo, M. Ashida and K. Hasezaki: Mater. Trans. 50 (2009) $167-170$.

14) K. E. Almin: Acta Chem. Scand. 2 (1948) 400-407.

15) R. C. Miller: Thermoelectricity: Science and Engineering, (1961) pp. 405-407. 